\title{
Del Código Civil al Estatuto de la Ciudad: algunas notas sobre la trayectoria del Derecho Urbanístico en Brasil
}

\begin{abstract}
This article pretends to explore some aspects of the conceptual and institutional process of construction of Urban Right in Brazil, discussing the context of juridical effective possibilities and concrete urban management political-institutional practices. At the same time, it attempts to establish a critical reflection about the process of production of urban laws, as well as their relationship with the social production of urban illegality. It is conclude that the approval of the City Statute in 2001 has contributed to consolidate the constitutional order in relation to the juridical control of urban development, with the objective of re-orient the public power action, the real state market and the society, in agreement with new urban, economic, social and environmental considerations.
\end{abstract}

Key words: urban right, process of urbanization, urban management, Brazil.

\section{Resumen}

Este artículo pretende explorar algunos aspectos del proceso de construcción conceptual e institucional del Derecho Urbanístico en Brasil, discutiendo el contexto de las posibilidades jurídicas efectivas y de las prácticas político-institucionales concretas de la gestión urbana. Al mismo tiempo, se intenta plantear una reflexión crítica acerca del proceso de producción de las leyes urbanísticas, así como su relación con la producción social de la ilegalidad urbana. Se concluye que la aprobación del Estatuto de la Ciudad, en el año 2001, ha contribuido a consolidar el orden constitucional en cuanto al control jurídico del desarrollo urbano, a objeto de reorientar la acción del poder público, del mercado inmobiliario y de la sociedad de acuerdo con nuevos criterios urbanísticos, económicos, sociales y ambientales.

Palabras clave: derecho urbanístico, proceso de urbanización, gestión urbana, Brasil. 


\section{Introducción}

I 10 de julio de 2001 fue aprobada en Brasil la Ley Federal № 10.257, Ilamada "Estatuto de la Ciudad", que regula el capítulo original sobre la política urbana aprobado por la Constitución Federal de 1988 (artículos 182 y 183). La nueva ley probablemente servirá para dar un soporte jurídico más consistente a las estrategias y los procesos de planeamiento urbano, y sobre todo a la acción de aquellos gobiernos municipales que se empeñan en enfrentar las graves cuestiones urbanas, sociales y ambientales que afectan directamente la vida de una gran parte $-82 \%$ de la población total- de los brasileños que viven en ciudades.

Más de diez años de discusiones y modificaciones fueron necesarios para que el proyecto de ley-que a su vez era una nueva encarnación de otros anteproyectos discutidos a lo largo de décadas- fuera finalmente aprobado. El texto final de la ley revela todas las dificultades del tenso proceso de negociación que se dio entre los diversos intereses acerca de la cuestión relativa al control jurídico del desarrollo urbano. Después de ser aprobada por el Congreso Nacional el 18 de junio de 2001, la nueva ley fue encaminada hacia la sanción y/ o veto del Presidente de la República, explorándose -y aun fomentándose- una polémica entre juristas por los sectores contrarios a la aprobación de varios de los principios e instrumentos de la nueva ley, en el sentido de argumentar su inconstitucionalidad y justificar así el veto presidencial. Al final de este proceso fueron vetados solamente algunos dispositivos sobre cuestiones específicas, pero la controversia jurídica no disminuyó.

Al reglamentar el capítulo constitucional sobre la política urbana, el Estatuto de la Ciudad confirmó de manera inequívoca el Derecho Urbanístico del derecho público brasile-

Diretor de Asuntos Fundiários, Secretaria Nacional de Programas Urbanos (Ministerio das Cidades). E-mail: edesiofernandes@compuserve.com ño. En lo que respecta a la relevancia de los nuevos instrumentos jurídicos y urbanísticos creados y/o reglamentados por la ley federal, creo que la principal importancia del Estatuto de la Ciudad se debe principalmente al marco conceptual consolidado, que si es debidamente asimilado, deberá tomarse como referencia central para la debida comprensión e interpretación de las muchas y complejas cuestiones jurídicas intrínsecas al proceso de uso, ocupación y división del suelo urbano, así como para dar soporte jurídico adecuado a las prácticas de gestión urbana.

Este artículo pretende explorar algunos aspectos de este proceso de construcción conceptual e institucional del Derecho Urbanístico en Brasil. Parto de la base que, dada la gravedad de los problemas urbanos existentes, estudiar el Derecho Urbanístico del siglo XXI en Brasil presupone discutir el contexto de las posibilidades jurídicas efectivas y de las prácticas político-institucionales concretas de la gestión urbana. Por la misma razón, por más fundamental que sea el estudio formal e integral de las leyes, principios e instrumentos jurídicos urbanísticos, la debida comprensión del Derecho Urbanístico, su naturaleza y sus posibilidades, requiere también de una reflexión crítica respecto del proceso de producción de tales leyes, las condiciones para que eso ocurra y los obstáculos para su cumplimiento, así como su relación con el proceso de producción social de la ilegalidad urbana. Por estas razones, es imperativo que los juristas establezcan los vínculos necesarios entre los estudios jurídicos y los estudios urbanos y ambientales, ya que solamente una visión interdisciplinaria del fenómeno de la urbanización intensiva puede dar cuenta de la complejidad de las cuestiones y los problemas jurídicos de las ciudades (Fernandes, 1998a).

Propongo como argumento que la debida validación crítica de esta dimensión jurídica del proceso de desarrollo urbano requiere un cambio de paradigma en la manera en que reflexionamos sobre estos dos temas básicos: si el Derecho Urbanístico y la gestión urbana no 
pueden ser estudiados separadamente, es necesario separar el tratamiento jurídico del derecho de propiedad inmobiliaria del ámbito individualista del Derecho Civil para ponerlo en el ámbito social del Derecho Urbanístico, de tal forma que el derecho colectivo para la planificación de las ciudades creado por la Constitución Federal de 1988 sea materializado. Del mismo modo, es necesario separar el tratamiento jurídico de la gestión urbana del ámbito restrictivo del Derecho Administrativo para ponerlo en el ámbito más dinámico del Derecho Urbanístico, de forma que el derecho colectivo de la gestión participativa de las ciudades, también creado por la Constitución Federal de 1988, sea efectuado.

\section{Función social de la propiedad vs. derecho individual no restringido}

A pesar de que fue frecuentemente enmascarada por discusiones aparentemente técnicas acerca de los aspectos formales, lo que siempre estuvo en juego durante el largo proceso de discusión sobre la nueva ley dentro y fuera del Congreso Nacional era -y todavía lo es- la fuerte resistencia de los grupos conservadores ligados al sector inmobiliario a la nueva concepción, propuesta por la Constitución Federal y consolidada por el Estatuto de la Ciudad, dada al derecho de propiedad inmobiliaria urbana, que es el principio constitucional de la función social de la propiedad y de la ciudad. Como último análisis, toda ley urbanística o ambiental implica materializar el principio de la función social de la propiedad, que es sin duda el principio fundamental del Derecho Urbanístico y del Derecho Ambiental.

Se trata del principio que venía repitiéndose a lo largo de todas las constituciones brasileñas desde 1934, sin que hubiera sido claramente definido o debidamente operado a través de la creación de mecanismos e instrumentos constitucionales y legales que permitieran y garantizaran su cumplimiento. Solamente en la Constitución Federal de 1988 el principio de la función social de la propiedad encontró una fórmula consistente, que pudo ser así sintetizada: el derecho de propiedad inmobiliaria urbana está asegurado desde que cumple su función social, que a su vez está determinada por la legislación urbanística, sobre todo en el contexto municipal. Es función del gobierno municipal promover el control del proceso de desarrollo urbano a través de la formulación de políticas de ordenamiento territorial, en las cuales los intereses individuales de los propietarios necesariamente coexisten con otros intereses sociales, culturales y ambientales de otros grupos y de la ciudad como un todo (Fernandes, 1995 y 1998c; Saule Jr., 1997).

Consecuentemente, fue dado al poder público el poder de -a través de leyes y diversos instrumentos urbanísticos- determinar la medida de este equilibrio (posible) entre intereses individuales y colectivos en cuanto a la utilización de este bien no renovable esencial al desarrollo sostenible de la vida en las ciudades, sean cuales sean: el suelo urbano.

Con todo, el principio de la función social de la propiedad es todavía en gran medida una figura retórica, ya que hace mucho que la acción de los sectores privados ligados al proceso de desarrollo urbano ha sido pautada por otro principio, que es el del derecho de propiedad individual no restringido. La base jurídica de este principio ha sido regulada por el Código Civil de 1916 -aprobado cuando apenas cerca de un $10 \%$ de los brasileños vivían en ciudades, en el contexto de un país todavía fundamentalmente agrario- pero que todavía se encuentra en vigor. Expresando la ideología del legalismo liberal, el Código Civil defiende el principio de la propiedad individual de forma casi absoluta. A lo largo del proceso de urbanización intensiva del país, y aunque pesen los cambios drásticos ocurridos en la sociedad brasileña en este periodo, la acción del poder público en el control del desarrollo urbano ha encontrado obstáculos en los principios civiles, que todavía orientan gran parte 
de la doctrina jurídica y de las interpretaciones de los tribunales (Grinberg, 2001).

El contenido de los cursos de derecho -que incluyen cuatro años y medio de discusiones formales sobre un Código Civil totalmente obsoleto en muchos aspectos- ha dificultado ciertamente el cambio de perspectiva sobre la cuestión; formados en esta tradición civilista, los juristas brasileños todavía miran la ciudad desde la perspectiva del lote privado, y naturalmente no ven -o no entiendenmucho más allá de los intereses individuales de los propietarios. Como mucho, aquellos juristas un poco más conscientes de la importancia de la acción del poder público en las áreas urbanas justifican la ampliación de algunas restricciones administrativas al ejercicio de la propiedad inmobiliaria. Con todo, se debe decir que, a pesar de la importancia de esta interpretación, se trata esencialmente de una reforma todavía insuficiente del paradigma liberal.

Culminando un proceso de reforma jurídica que empezó en la década de 1930, lo que la Constitución de 1988 y el Estatuto de la Ciudad proponen es exactamente este cambio de perspectiva; es decir, y partiendo del nuevo paradigma conceptual de comprensión e interpretación, se propone sustituir el principio individualista del Código Civil por el principio de la función social de la propiedad, que -dígase de paso- se encuentra presente de manera central en el orden jurídico de muchos de los países capitalistas más desarrollados.

Antes de la aprobación del Estatuto de la Ciudad, la resistencia al principio constitucional de la función social (al igual que otras leyes urbanísticas, sobre todo las leyes municipales) era frecuentemente expresada a través del argumento jurídico -equívoco pero eficiente- de que el capítulo constitucional no sería autoaplicable, con lo que era necesario que una ley federal lo reglamentara, ya que solamente otra ley federal podría modificar los principios del Código Civil sobre el derecho de propiedad. En falta de una ley federal que tratase del proceso de desarrollo urbano, la acción del poder público en este campo tenía que ser justificada por malabares intelectuales relacionando diversos principios constitucionales en vigor que trataban aspectos parciales de la cuestión. Más de doce años después de la creación de la Constitución de 1988, una ley federal finalmente entró en vigor, con lo que este viejo argumento ya no puede ser utilizado.

La verdad es que, por tratarse de un tema tan central del orden económico capitalista, la discusión sobre el Derecho Urbanístico es con frecuencia atravesada por representaciones ideológicas no siempre explícitas, generando situaciones ambiguas y actitudes contradictorias por parte del poder público (inclusive del poder judicial, de los juristas y de la propia sociedad). Son muchos los "mitos" que deben ser aclarados para que la discusión sobre el Derecho Urbanístico se centre en un cuadro de mayor objetividad, apoyado en análisis conceptuales e investigaciones empíricas, de acuerdo con los principios de racionalidad académica más evidentes y en consonancia con los principios contemporáneos expresados en los diversos tratados y convenciones internacionales que Brasil ha firmado frecuentemente.

\subsection{Los derechos de propiedad}

Basándose en muchas de las críticas a la nueva ley, se percibe una visión ideológica común a los juristas conservadores respecto de que existiría un único derecho de propiedad "natural", intocable y casi sagrado; al respecto, es necesario que los juristas entiendan que, tanto en el ordenamiento jurídico brasileño como en el del resto de países capitalistas, no se menciona a la definición jurídica del derecho de propiedad como ahistórica, pues todo orden jurídico es histórica, cultural y políticamente producido y modificado. Al centrarse en exceso en el positivismo y el formalismo jurídico, conscientemente o no, estos juristas han estado al servicio de intereses económicos que ven solamente en las ciudades el palco para la acumulación del capital, sin preocuparse de 
otros intereses sociales y ambientales que hacen referencia a la utilización del suelo urbano.

Además, argumentar que en el orden jurídico brasileño existe un concepto único de derecho de propiedad es una falacia: son muchas las formas de derecho de propiedad -inmóvil, móvil, pública, privada, rural, urbana, intelectual, financiera, industrial, etc.-, así como son diversas las relaciones sociales establecidas en torno a ellas, siendo cada forma específica tratada de manera diferente por el orden jurídico. El principio liberal del Código Civil ya ha sido profundamente modificado en lo que se refiere a estos derechos, permitiendo la intervención creciente del Estado en el dominio económico de la propiedad hasta tal punto, que hoy se discute la conveniencia 0 no de la retirada del Estado del escenario económico y el nuevo lugar del mercado. Es en lo que se refiere a una forma específica de propiedad -la propiedad inmobiliaria- que todavía no ha sido reformado el liberalismo jurídico clásico por el Estado brasileño, por razones históricas y políticas (Fernandes, 1995 y 2000b; Fernandes \& Rolnik, 1998).

Proceder a ese cambio de paradigma, sobre todo en el contexto de las decisiones judiciales, es de importancia fundamental. La tradición incipiente de estudios jurídicos urbanísticos en Brasil tiende a ser esencialmente legalista, reforzando el principio civil del derecho de propiedad individual y no restringido. El Código Civil todavía considera la tierra y el derecho de propiedad inmobiliaria casi exclusivamente en función de las posibilidades económicas ofrecidas a los propietarios individuales, cuya medida es determinada por los mismos, reduciendo sobre todo el ámbito de la acción del Estado en el control de los procesos de uso y ocupación del suelo urbano para hacer compatibles los diferentes intereses existentes en el desarrollo urbano.

Las ciudades brasileñas -fragmentadas, excluyentes, segregadas, ineficaces, caras, contaminadas, peligrosas, injustas e ilegalesson en gran medida el resultado del fracaso del Estado en la reforma del orden jurídico liberal, ya que la lógica especulativa del mercado ve en la propiedad solamente un valor de cambio, es decir, solamente una mercancía, y no da cuenta de las cuestiones sociales y ambientales. Tan importante como aprobar nuevas leyes y crear nuevos instrumentos es consolidar el paradigma propuesto por la Constitución de 1988, con el objetivo de reformar para siempre la tradición civilista que está a la base de gran parte de la resistencia ideológica a las políticas urbanas progresistas, y que no considera el papel central de la ley -y de la ilegalidad-en el proceso de desarrollo urbano y de gestión urbana.

El mayor distanciamiento se debe a la necesidad de comprender que el principio de la función social de la propiedad no puede ser confundido con las restricciones administrativas externas al ejercicio del derecho de propiedad, como muchos juristas han afirmado: el principio constitucional es esencial para la propia caracterización y conformación del derecho de propiedad, calificando internamente las formas de uso, gozo y disposición de los bienes inmobiliarios. En ese sentido, el derecho de propiedad inmobiliaria deja de tener un contenido económico predeterminado -cuya medida sería dada por los intereses individuales del propietario-y pasa de tener un contenido económico a ser determinado por el poder público a través de las leyes, planes y proyectos urbanísticos, una vez considerados también los otros intereses sociales, ambientales y culturales respecto de la utilización del suelo y de los bienes inmobiliarios.

Solamente la instauración inequívoca de ese nuevo marco conceptual del Derecho Urbanístico puede llevar a la materialización del nuevo derecho colectivo fundamental creado por la Constitución de 1988, que es el derecho de todos los ciudadanos a contar con el desarrollo de sus ciudades planeado de acuerdo no sólo con los intereses individuales de 
los propietarios inmobiliarios, sino sobre todo de acuerdo con los intereses sociales de la comunidad-y de la ciudad-como un todo.

\section{Derecho Urbanístico y gestión urbana}

Como he argumentado anteriormente, la discusión sobre el Derecho Urbanístico debe darse en el contexto de su relación con las prácticas concretas de gestión urbana (Fernandes, 2000a y 2001b). De hecho, algunas de las experiencias internacionales más innovadoras de gestión urbana están teniendo lugar en Brasil, como el presupuesto participativo introducido por el municipio de Porto Alegre, el cual viene siendo implementado en diversas ciudades. La aprobación del Estatuto de la Ciudad consolidó un nuevo paradigma no sólo para la planificación urbana, sino también para la gestión urbana, especialmente por el hecho de reglamentar instrumentos jurídicos de implementación de políticas urbanísticas tales como edificación obligatoria, transferencia del derecho de construir, expropiación con pago en títulos de la deuda pública, impuesto progresivo de bienes inmobiliarios y usucapión especial urbana.

Por un lado, el debido tratamiento jurídico del derecho de propiedad inmobiliaria debe ser retirado del contexto individualista del Derecho Civil, de forma que pueda ser interpretado a partir de los criterios más progresistas de orden público del Derecho Urbanístico. Por otro lado, las posibilidades y condiciones ofrecidas por el Derecho Administrativo tradicional tampoco son satisfactorias para la promoción de una gestión urbana eficiente, justa y democrática. Los principios e instrumentos en vigor -limitados, restrictivos y formalistas- no tienen la necesaria flexibilidad y el alcance debido para manejar y garantizar la seguridad jurídica y las relaciones político-institucionales que están transformándose rápidamente en varios niveles: dentro del entorno estatal más amplio, entre niveles gubernamentales, entre Estado y sociedad y al interior de ésta. Diversas estrategias de planeamiento urbano han sido formuladas con base en nuevas ideas de gestión urbana tales como suelo creado, asociación públicoprivado, operaciones urbanas y operaciones interligadas, privatización y terciarización de la prestación de servicios públicos -aparte del propio presupuesto participativo-, pero dichas estrategias todavía no encuentran un soporte pleno y adecuado en el orden jurídico administrativo.

Más que nunca, dada la extensión y diversidad de los problemas del país, los juristas deben preocuparse no sólo de la interpretación formal de las leyes, sino también de las condiciones de efectividad de las normas y la necesidad del cumplimento de las leyes, políticas y programas urbanos, así como de las promesas de reformas socioeconómicas y políticas en ellas contenidas. La cuestión de la gestión urbana involucra aspectos y consideraciones transdisciplinarias que, más allá de la necesidad de una integración entre los profesionales de las diversas áreas, requieren -entre otros factores- de la capacidad técnica y financiera de los gobiernos municipales, la difusión de la información sobre las leyes existentes y el combate a la corrupción. Desde la perspectiva jurídica más inmediata, la discusión sobre la gestión urbana (su naturaleza, sus problemas, obstáculos y posibilidades) requiere la integración de tres dimensiones interrelacionadas: gestión político-institucional, gestión político-social, y gestión político-administrativa. Las dos primeras dimensiones se encuentran tradicionalmente en el ámbito del Derecho Constitucional; la última, en la esfera del Derecho Administrativo. La propuesta del Derecho Urbanístico público es integrarlas de manera renovada.

La gestión político-institucional tiene que ver con las condiciones de organización del Estado, y la verdad es que el "mapa" del federalismo brasileño no coincide con el "mapa" de la urbanización en el país; en otras palabras, el pacto político-institucional federativo no expresa la realidad urbana-territorial 
creada en el país. Muchos han sido los problemas causados por este descompás fundamental; hasta la promulgación de la Constitución Federal de 1988, varios de ellos se debían a factores y procesos complejos, como las condiciones distorsionadas de la distribución de las competencias legislativas, la falta de autonomía municipal y la centralización de los poderes políticos, jurídicos y financieros, el entorno autoritario de la gestión metropolitana que entró en vigor entre 1973 y 1988 y el tratamiento formal idéntico otorgado a municipios completamente diferentes, etc. (Fernandes, 1985 y 1992).

A pesar de su importancia, las tentativas de enfrentamiento de tales problemas en el periodo inmediatamente anterior a la convocación del Congreso Nacional Constituyente -por ejemplo, a través de la creación de asociaciones y consorcios de los municipios- eran jurídica y políticamente frágiles. Como resultado, surgió el movimiento de "municipalización a cualquier costo", el cual -para bien o para mal- orientó la formulación de la Constitución Federal de 1988. Desde entonces, pese al reconocimiento de una autonomía municipal relativamente mayor, diversos problemas siguen afectando las condiciones de la gestión político-institucional, tales como la falta de tratamiento adecuado de la dimensión metropolitana del ordenamiento territorial, el crecimiento artificial de algunos municipios, relaciones intergubernamentales político-financieras poco sistemáticas, etc. Este cuadro se ha visto complicado aún más por la cantidad de problemas fiscales, financieros, sociales, urbanos y ambientales acumulados, y que requieren con urgencia una amplia acción integrada de los entes federativos.

La gestión político-social tiene que ver con la relación amplia entre el Estado y la sociedad. La verdad es que, por varias razones, el orden jurídico-político constitucional no expresa el orden político-social construido en el cotidiano de los procesos políticos del país. Algunos problemas existentes hasta la promulgación de la Constitución Federal de
1988 se referían a la exclusión popular del proceso político, esencialmente autoritario, incluso debido al hecho de que los alcaldes de las capitales, hasta 1982, no eran elegidos; elección indirecta del Presidente de la República hasta 1988; poder legislativo impedido -en todos los niveles gubernamentales- de proponer leyes en materia financiera y presupuestal; uso indiscriminado de medidas de excepción como el decreto-ley; sistema electoral excluyente; mecanismos de representación popular viciados; etc. Las tentativas de enfrentamiento de estos problemas, formuladas sobre todo desde fines de la década de 1970, con la crisis creciente de legitimidad del Estado y frente al surgimiento de nuevas formas de organización social como movimientos sociales, sindicatos fuertes, etc., resultaron en la importante creación de consejos, comisiones y comités con participación creciente de la sociedad civil.

Después de 1988, entre muchos otros problemas político-sociales existentes, se puede destacar el hecho de que, aunque la Constitución proponga la combinación entre democracia representativa y democracia directa de variadas formas, el fortalecimiento del poder legislativo ha llevado a tensiones con los mecanismos de participación popular-presupuesto participativo, consejos deliberantes, etc.que se dan en el seno del Ejecutivo; al mismo tiempo, la estructura del poder judicial fue lamentablemente poco alterada, así como también el sistema electoral, etc. En fin, son muchos los problemas que necesitan ser urgentemente confrontados.

Desde la perspectiva de la gestión político-administrativa, también hay muchas cuestiones complejas por ser enfrentadas. Con la crisis fiscal, la redefinición del papel del Estado originado por las políticas de liberalización, las presiones relativas a la globalización económica, el incremento de la pobreza social, los avances tecnológicos, etc., ha habido una presión creciente por flexibilidad en la planificación urbana y la acción administrativa, de forma tal que puedan ser dadas respuestas 
más rápidas a las cuestiones urbanas. Surgieron entonces los principios de asociación público-privado, operaciones urbanas, operaciones interligadas y ganancias de la planificación, siempre con énfasis en la idea del regateo, del crédito y la estimulación. En base a dichas estrategias se plantea una crítica a la burocratización excesiva del Derecho Administrativo en vigor, así como a la rigidez de las reglas que orientan el contrato administrativo y a la inflexibilidad de los principios que rigen la relación entre el Estado y el sector privado. Con todo, otros problemas igualmente serios tienen su origen en los cambios en las prácticas de la gestión político-administrativa: las nuevas estrategias adoptadas frecuentemente no se han basado en criterios transparentes; la seguridad jurídica de las nuevas relaciones entre el sector estatal y el sector privado ha sido cuestionada; la falta de criterios y de control en las decisiones tomadas han hecho que nuevos espacios hayan sido abiertos para corrupción, favorecimiento político y "amiguismo", etc.

También en el contexto de la gestión urbana, es fundamental que el paradigma del Derecho Urbanístico sea consolidado para crear una verdadera esfera pública que no se vea reducida al sector estatal, y que sea efectivamente democrática y participativa, para que así sea materializado el otro nuevo derecho colectivo creado por la Constitución Federal de 1988, que es el derecho colectivo a la participación directa e indirecta de todos en el proceso de gestión de las ciudades.

\section{Ciudades ilegales}

Tal y como he destacado anteriormente, no es posible hablar de Derecho Urbanístico en el Brasil actual sin hablar de ilegalidad urbana. La proliferación de las formas de ilegalidad en las ciudades, especialmente en el contexto cada vez más significativo de la economía informal, es una de las mayores consecuencias del proceso de exclusión social y segregación espacial que ha caracterizado el crecimiento urbano intensivo en los países en desarrollo. Este fenómeno se vuelve aún más importante en lo que refiere a los procesos socioeconómicos y culturales de acceso al suelo y producción de la vivienda: un número cada vez mayor de personas han tenido que incumplir la ley para tener un lugar en las ciudades, viviendo sin seguridad jurídica de la tenencia en condiciones precarias, insalubres y peligrosas, generalmente en zonas periféricas o en áreas centrales desprovistas de infraestructura urbana adecuada. Diversos estudios han revelado que, consideradas dichas formas de acceso al suelo urbano y de producción de la vivienda, entre un 40\% y un $70 \%$ de la población urbana en las grandes ciudades de los países en desarrollo están viviendo ilegalmente (tales índices llegan a 80\% en algunos casos). Datos recientes de los municipios de Sao Paulo y Río de Janeiro han reconocido que por lo menos un $50 \%$ de su población vive ilegalmente.

Ese fenómeno complejo ha atraído cada vez más la atención de investigadores a nivel internacional, y diversas publicaciones han registrado sus conclusiones (Fernandes \& Varley, 1998; Fernandes, 1999c y 2001a). En cuanto a sus especificaciones, la discusión sobre la ilegalidad urbana tiene que ceñirse al contexto más amplio de la reflexión sobre el papel central que el derecho -comprendiendo no solamente las leyes existentes, sino también los principios jurídicos, las decisiones judiciales y la dinámica más amplia del orden jurídico- ha tenido en la determinación del patrón de crecimiento urbano en los países en desarrollo. De hecho, la discusión crítica sobre la ley y la ilegalidad en el contexto del desarrollo urbano ha ganado protagonismo en los últimos años, especialmente desde que la Agenda Habitat de la ONU resaltó la importancia fundamental del Derecho Urbanístico ${ }^{1}$.

La Agenda Habitat es el plan global de acción adoptado por la comunidad internacional en la Conferencia Habitat II de la ONU, realizada en Estambul (Turquía) en junio de 1996. 
No hay que seguir ignorando el hecho de que la legalidad e ilegalidad son dos caras del mismo proceso social de producción del espacio urbano. La ilegalidad urbana tiene que ser comprendida no solamente en términos de la dinámica entre sistemas políticos y mercados de tierras, sino también en función de la naturaleza del orden jurídico en vigor, sobre todo en lo que se refiere a la definición de los derechos de propiedad inmobiliaria urbana. Desde mediados de la década de 1990, juristas y no juristas han debatido en Brasil cada vez más las causas e implicancias del proceso creciente de ilegalidad en las ciudades, partiendo de -y combinando- diversas perspectivas: jurídica, sociológica, política, económica, ambiental y antropológica². Diversos estudios han explorado la relación entre la legislación de la planificación urbana, la exclusión social y la segregación espacial; más recientemente, se asocia otro factor importante a esa ecuación, cual es la creciente violencia urbana (Rolnik, 1999).

En suma -y como lo ha indicado también la Agenda Habitat-, ha quedado cada vez más claro que la promoción de la reforma urbana depende en parte de la promoción de una reforma jurídica amplia, sobre todo en lo que refiere a la regulación de los derechos de propiedad inmobiliaria y del proceso más amplio de desarrollo, planificación y gestión urbana. La Campaña Global de la ONU por la Buena Gobernanza Urbana revela también que la promoción de la reforma jurídica ha sido vista por organizaciones nacionales e internacionales como una de las principales condiciones para el cambio del patrón excluyente de desarrollo urbano en los países en desarrollo y en transición, y para la efectiva confrontación de la ile-

2 Entre otros colegas juristas que han escrito y publicado frecuentemente sobre el tema, merecen destacarse Betania de Moraes Alfonsin, Jacques Alfonsin, Leticia Marques Osorio y Nelson Saule Jr.; entre los no juristas, deben ser destacados los trabajos pioneros, combativos e imprescindibles de Enninia Maricato y Raquel Rolnik. galidad urbana ${ }^{3}$. En especial, es fundamental que se reconozca que, en casos como Brasil, donde la ilegalidad urbana dejó de ser la excepción y pasó a ser la regla, se trata más bien de un fenómeno estructural a los procesos de producción de la ciudad, y necesita ser enfrentada como tal, requiriéndose la formulación de directrices y estrategias específicas en el contexto más amplio del planeamiento y gestión urbana, y no meramente a través de políticas sociales y/o urbanísticas aisladas y marginales.

Hay otros aspectos de ese proceso que necesitan ser brevemente mencionados: en primer lugar, y a juzgar por las reacciones de las autoridades y de la propia opinión pública, parece ser que existen en Brasil "grados de ilegalidad"; es decir, algunas prácticas de ilegalidad urbana son más toleradas y más justificables que otras, las cuales provocan la acción represiva del Estado. En general, se puede decir que la mayor o menor tolerancia de las prácticas de ilegalidad tiene que ver con la existencia de documentos formales -por más jurídicamente precarios que sean-que sugieren una tentativa de continuidad en la cadena de transmisión de las propiedades (Fernandes, 1997). Además, hay que recordar que las prácticas de ilegalidad en las formas de acceso al suelo y a la vivienda no son en modo alguno restrictivas a los pobres. De hecho, son muchos los ejemplos de prácticas ilegales verificadas entre los grupos más privilegiados, que van desde la frecuente falta de respeto a las normas urbanísticas hasta los llamados "condominios cerrados", que entre otros efectos negativos, impiden la libre circulación y el libre acceso a las playas, las cuales son bienes de uso común. En cuanto a esas formas de ilegalidad, la regla ha sido la impunidad. Finalmente, la crisis generalizada del orden jurídico ha llevado a la proliferación de formas informales de distribución de la justicia cada vez

3 Véase el sitio del UNCHS-United Nations Centre for Human Settlements (Habitat) www.unchs.org/ govern para información sobre la Campaña Global para la Buena Gobernanza Urbana. 
más "sofisticadas", asimilables sobre todo a la cotidianidad de las comunidades excluidas del acceso al sistema jurídico oficial. Tales prácticas cumplen naturalmente con importantes funciones sociales, políticas e ideológicas, pero en esencia, este fenómeno resulta peligroso, ya que pone en evidencia los patrones básicos de la organización sociopolítica del país (Fernandes, 1999b y 2001a) ${ }^{4}$.

\section{Regularización de asentamientos informales}

Una de las cuestiones que más ha ocupado a los juristas involucrados en la cuestión urbana a nivel internacional hace referencia a los programas de regularización de asentamientos informales que han sido implementados en varios países. Preocupados de las graves implicancias sociales, económicas, ambientales y políticas del proceso de ilegalidad urbana, sobre todo para la población pobre (en especial mujeres y niños), a lo largo de las dos últimas décadas administradores y planificadores urbanos de diversas ciudades latinoamericanas, africanas y asiáticas han buscado formular también -con mucha dificultad- programas de regularización de la tenencia de asentamientos informales, buscando promover la urbanización de estas áreas y el reconocimiento, en alguna medida, de los derechos de sus ocupantes. Esa necesidad de enfrentamiento urgente a la ilegalidad urbana, con el objeto de promover la integración socioespacial de los grupos que viven en asentamientos informales, es el tema central de la Campaña Global por la Seguridad de la Tenencia que viene siendo promovida desde 1999 por la agencia Habitat de la ONU55.

$4 \quad$ La tradición de estudios sobre el fenómeno de la justicia informal y del pluralismo jurídico se debe a la contribución pionera fundamental de Boaventura de Sousa Santos.

5 Véase el sitio del UNCHS-United Nations Centre for Human Settlements (Habitat) www.unchs.org/ tenure para información sobre la Campaña Global por la Seguridad de la Tenencia.
En Brasil, estos programas de regularización han sido implementados en diversos municipios -como Porto Alegre-desde mediados de la década de 1980, y sobre todo a partir del inicio de la década de 1990, cubriendo tanto las favelas como -en una escala menor- los llamados "loteos clandestinos" y/o "irregulares". De hecho, entre otras formas de ilegalidad urbana, la proliferación de favelas y loteos clandestinos/irregulares es una de las consecuencias más importantes del proceso de exclusión socioespacial que ha caracterizado el crecimiento urbano en el país. A lo largo de las décadas de urbanización intensiva, dada la combinación entre la falta de una política habitacional de alcance social y la ausencia de opciones asequibles y adecuadas ofrecidas por el mercado inmobiliario, un número cada vez mayor de brasileños han tenido en las favelas y en los loteos periféricos la única forma posible de acceso al suelo urbano y a la vivienda. Más recientemente, con el aumento significativo de la pobreza urbana, la adquisición de lotes en loteos ilegales se ha vuelto prohibitiva para una parte cada vez mayor de la población, con lo que el número de favelas han crecido desorbitadamente en las áreas periféricas de diversas ciudades, junto con una mayor densidad de ocupación de las favelas centrales ya existentes. A falta de políticas habitacionales adecuadas, corticos e invasiones -generalmente en áreas inadecuadas para la ocupación humana- han sido las formas contemporáneas de acceso a la vivienda en las ciudades.

El papel de la legislación en ese proceso de producción de la ilegalidad urbana y de la segregación espacial se destaca especialmente-como he insistido- en lo que refiere a la visión individualista y excluyente de los derechos de propiedad inmobiliaria todavía vigentes en el país. Además, se debe resaltar el papel importante cumplido por las leyes elitistas y socialmente inadecuadas que han obviado históricamente las realidades de los procesos socioeconómicos de producción de la vivienda, exigiendo patrones técnicos y urbanísticos inalcanzables, acabando por reservar las áreas nobles y provistas 
de infraestructura para el mercado inmobiliario a las clases media y alta, ignorando así las necesidades de vivienda de los grupos menos favorecidos. Tal proceso ha sido agravado por la falta de políticas urbanísticas y fiscales efectivas en el combate a la especulación inmobiliaria (Rolnik, 1997; Maricato, 1996).

De igual manera, las posibilidades ofrecidas por el cuadro jurídico en vigor para la formulación de políticas de regularización fundiaria necesitan ser comprendidas de mejor manera, sobre todo por aquellos gobiernos municipales comprometidos con propuestas de democratización de las formas de acceso al suelo y a la vivienda. Dar respuestas adecuadas a los problemas complejos originados por la ilegalidad urbana es difícil, y las soluciones particulares no siempre pueden ser repetidas en otros casos. En último análisis, un programa de regularización exitoso depende de una acción gubernamental sistemática, y requiere tanto inversiones en dinero como una promoción de reformas jurídicas.

Aunque se reconozca el carácter paliativo de estos programas y la necesidad de inversiones públicas y políticas sociales que efectivamente entreguen opciones de vivienda social asequibles y adecuadas, sobre todo en las áreas centrales de las ciudades, la legitimidad de los programas de regularización de los asentamientos informales existentes es innegable, y puede ser claramente justificada sea por razones pragmáticas, sea por involucrar derechos fundamentales. De modo general, los programas de regularización de favelas en Brasil han sido más sistemáticos y consistentes que los programas de regularización de loteos, reflejando una mayor movilización de los moradores en favelas, lo que quizás pueda ser explicado por su condición jurídica más precaria y su mayor vulnerabilidad política y socioambiental. Porto Alegre es uno de los pocos municipios brasileños donde una po- lítica consistente de regularización de loteos está siendo implementada.

Por otra parte, las favelas son contemporáneas del proceso de urbanización, y el fenómeno ha sido ampliamente investigado y analizado en Brasil y otros países. Junto con el caso de Brasilia, la experiencia de Belo Horizonte - ciudad planificada-expresa de manera inequívoca la naturaleza excluyente del proceso de desarrollo urbano y el patrón segregador de las relaciones históricas que se han dado entre legislación, planificación urbana, mercado inmobiliario y sociedad, sobre todo en la creación de la dinámica y posibilidades del mercado y en la determinación del lugar de los pobres en la ciudad. En Belo Horizonte, cuando las necesidades de los pobres constructores de la ciudad fueron ignoradas por los planificadores urbanos, se constituyeron las primeras favelas, antes incluso de la inauguración oficial de la ciudad: en 1895, cerca de 3.000 personas ya vivían en favelas en la nueva ciudad que estaba siendo construida. Cerca de 100.000 familias viven actualmente en favelas en Belo Horizonte, lo que equivale a más del $20 \%$ de la población total, siendo en otras ciudades como Salvador y Recife, un porcentaje superior al $40 \%$ (Fernandes, 1998b).

En Belo Horizonte, como en varias otras ciudades brasileñas como Porto Alegre y Recife, y dada la creciente movilización social de los favelados reivindicando el reconocimiento de sus derechos y la urbanización de las favelas, las políticas públicas municipales han avanzado a lo largo de varias décadas en el sentido de reconocer en alguna medida el derecho de los favelados a tener un lugar más adecuado en el espacio de la ciudad. A partir de la década de 1970, en varios municipios las expulsiones violentas y remociones forzadas fueron siendo gradualmente sustituidas por la relativa tolerancia de estas formas de ocupación ilegal, culminando con el reconocimiento oficial de algunas de las áreas de las favelas y de los derechos de las comunidades que en ellas viven. 
También en esa nueva realidad Belo Horizonte constituye una referencia fundamental en el contexto brasileño. La ley que creó el "ProFavela" de Belo Horizonte en 1983 fue pionera al proponer un programa social de regularización de las favelas, introduciendo una fórmula original: la combinación entre la identificación y demarcación de favelas como áreas residenciales para fines de vivienda social -inicialmente denominadas "sectores especiales"- en el contexto de la planificación del territorio municipal; la definición de normas urbanísticas especificas de uso, división y ocupación del suelo en dichas áreas y la creación de mecanismos político-institucionales de gestión participativa de los programas de regularización. Esta fórmula acabó convirtiéndose en un paradigma seguido por otras ciudades como Recife, Salvador y Porto Alegre, en las cuales también fueron creadas "zonas/áreas especiales de interés social", con patrones urbanísticos propios y sometidas a un proceso participativo de gestión institucional (Alfonsin, 1997 y 2001).

De hecho, la creación de zonas residenciales especiales para fines de vivienda social, dentro de la ley que regula las áreas municipales, ha sido considerada un gran avance por cuanto permite redefinir -o por lo menos minimizaren parte la dinámica del mercado inmobiliario, garantizando así los espacios en el territorio de la ciudad para los grupos pobres. Ese modelo ha sido exportado a otros países, sobre todo en África, en parte por el reconocimiento internacional de las innovaciones de las experiencias brasileñas, y en parte también debido a la acción de ONG extranjeras como la GTZ y la AVSI, que actuaron en ciudades brasileñas. En Brasil, combinando políticas de urbanización (implementación de infraestructura y prestación de servicios) y políticas de legalización de las áreas y lotes individuales, y aunque con diferencias, casi todos los programas de regularización de favelas han sido estructurados en torno a dos objetivos principales, los cuales son el reconocimiento de alguna forma de seguridad jurídica de la tenencia para los ocupantes de las favelas, así como la integración socioespacial de estas áreas y comunidades en el contexto más amplio de la estructura y de la sociedad urbana. Se debe mencionar que las políticas de legalización que intentan proveer de seguridad jurídica a la propiedad requieren una atención aún mayor en lo que se refiere a las implicaciones del género del proceso.

Con todas sus limitaciones, estos programas han sido más exitosos en lo que se refiere a las políticas de urbanización que a las políticas de legalización, viéndose beneficiadas a lo largo de años de inversiones públicas muchas favelas, las cuales están mejor equipadas, con infraestructura urbana y servicios públicos, que los loteos ilegales de las periferias de las ciudades (Fernandes, 1999a).

En particular, los planificadores y administradores urbanos - sobre todo aquellos que trabajan en las agencias de regularización- deben tomar conciencia acerca de las amplias ( $y$ a veces perversas) implicancias de sus propuestas, especialmente en lo que se refiere a la legalización de los asentamientos informales. El reconocimiento de los tan aclamados derechos sociales de la vivienda no puede ser reducido al reconocimiento de los derechos individuales de propiedad. De hecho, la legalización de las actividades informales, particularmente a través del reconocimiento de los títulos individuales de la propiedad plena, no implica automáticamente la integración socioespacial. Por el contrario, si no fueran formulados dentro del ámbito de las políticas socioeconómicas comprensivas, los programas de regularización de la tenencia pueden tener otros efectos indeseados (como nuevos cargos financieros para los ocupantes), teniendo un impacto poco significativo en la reducción de la pobreza urbana, y lo que es aún más importante, reforzando directamente el conjunto de fuerzas económicas y políticas que han causado tradicionalmente la exclusión social y la segregación espacial (Payne, 2001).

\subsection{Legalidad e ilegalidad}

Es necesario que juristas, planificadores y administradores urbanos comprendan que 
existe una relación directa entre la ilegalidad urbana y la naturaleza del orden jurídico en vigor. La incuestionada sobrevivencia de la legalidad liberal en lo que concierne a la propiedad de la tierra se debe naturalmente a una combinación histórica de factores sociales, políticos y económicos que posibilitaron la formación y sobrevivencia de la estructura de propiedad de la tierra altamente concentrada del país, los cuales han de ser comprendidos antes de que cualquier programa de legalización pueda ser implementado (Maricato, 2000). Las principales cuestiones siguen sin ser respondidas por los juristas, porque ellos tampoco las tienen claras: ¿Qué tipo de implicancias ha tenido el orden jurídico en el proceso del crecimiento urbano, y quién se ha beneficiado de la mantención incuestionada del statu quo?

La búsqueda de soluciones jurídico-políticas innovadoras para las políticas de legalización de la tenencia requiere de la compatibilidad entre la promoción de seguridad individual de la propiedad y el reconocimiento de los derechos sociales de vivienda, y de la tentativa de minimización de los impactos de tales políticas en el mercado, de forma tal que los beneficios de la inversión pública sean capturados directamente por sus ocupantes, y no por los promotores inmobiliarios privados. Perseguir esos objetivos es de fundamental importancia dentro del contexto más amplio de la promoción de una estrategia de reforma urbana que busque promover la inclusión socioespacial. Diversas ciudades, como Porto Alegre y Belo Horizonte, han intentado manejar la agenda urbana progresista con la reforma de su orden jurídico; avances significativos han incluido, más allá de la creación de las zonas de interés especial, la aprobación de normas y reglamentaciones urbanísticas menos elitistas, así como el enfrentamiento de la naturaleza excluyente de los mecanismos fiscales de captura del valor de la tierra, a fin de tornarlos menos regresivos.

El mayor aprendizaje de las experiencias brasileñas e internacionales de regularización de asentamientos informales dice relación con el hecho que, a pesar de que generan efectos negativos, las políticas de legalización no pueden ser formuladas en forma aislada, y no se dan por fuerza de ley o decreto. Un factor fundamental para que la discusión sobre tales programas y políticas sea efectivamente incluida en el contexto más amplio de la agenda de las políticas sociales y urbanísticas de la ciudad es ciertamente la participación popular en las varias instancias del proceso de su discusión, formulación e implementación -participación que es también lo que garantiza la legitimidad de los programas y políticas de regularización.

Con todo, se debe decir que la resistencia ideológica a los programas de regularización de favelas ha crecido, siendo muchas veces expresada a través de argumentos ambientales. Aun pese al papel fundamental que la institución ha tenido en la construcción de un orden público en Brasil, el propio Ministerio Público con frecuencia opone valores ambientales a valores sociales como el derecho social-constitucional a la vivienda, aun en áreas urbanas (públicas y privadas) donde los asentamientos humanos han sido consolidados a lo largo de varias décadas de ocupación informal.

La medida de tal resistencia ideológica puede ser percibida por la lectura inversa de los términos de una decisión judicial reciente: en una acción en contra de las personas de condición económica privilegiada que habían construido verdaderas mansiones en un "condominio cerrado" en un área pública, el juez negó el pedido de demolición de las casas bajo el argumento de que, a pesar de la ilegalidad manifiesta de la ocupación, no se podía ignorar que el dinero había sido invertido en las construcciones y que había generado empleos. Se debe preguntar si el mismo argumento sería aceptado en el caso de que esta acción propusiera el desplazamiento de los favelados.

\section{La autonomía del Derecho Urbanístico}

Muchos de los -todavía pocos-juristas que se han ocupado de la cuestión urbana lo hacen 
todavía a través de la perspectiva restrictiva del Derecho Administrativo. Mientras las ciudades y sus problemas crecen de manera preocupante, y a pesar del hecho de que miles de leyes urbanísticas han sido aprobadas en todos los niveles de gobierno desde la década de 1930 -sobre todo a lo largo de las tres últimas décadas-, estos juristas todavía pierden tiempo en discusiones sin sentido acerca de la autonomía del Derecho Urbanístico. En términos generales, el Derecho Urbanístico solamente ha sido aceptado como un sub-ramo del Derecho Administrativo, o en algunos casos, del Derecho Ambiental. Como he insistido, creo que tal resistencia es de naturaleza ideológica y tiene que ver con nociones preconcebidas e incuestionadas acerca del derecho de propiedad inmobiliaria. La mayor aceptación del Derecho Ambiental parece deberse en parte al hecho de que la "agenda verde" es frecuentemente expresión de una visión naturalista respecto de un espacio abstracto y sin conflictos, siendo ciertamente más próxima a la sensibilidad de las clases medias de lo que lo es la "agenda marrón" de las ciudades contaminadas, estructuradas a partir de los conflictos político-sociales y jurídicos en torno a la tierra y las relaciones de la propiedad.

La verdad es que se ha avanzado mucho desde que las posibilidades de acción del Estado en el control de la propiedad inmobiliaria y del desarrollo urbano estaban limitadas al binomio usucapión/expropiación. Del Código Civil de 1916 al Estatuto de la Ciudad de 2001, es decir, del principio de la propiedad individual irrestricta al principio de las restricciones urbanísticas al derecho de propiedad, hasta llegar al principio de la función social de la propiedad y de la ciudad, el orden jurídico del control del desarrollo urbano fue totalmente reformado. En ese contexto, no hay manera de negar la autonomía académica y políticoinstitucional del Derecho Urbanístico, no solamente por las referencias explícitas hechas a esa rama del derecho en la Constitución Federal de 1988, sino también por el hecho de que fueron claramente cumplidos todos los "criterios" tradicionalmente exigidos para el re- conocimiento de la autonomía de una rama del derecho: el Derecho Urbanístico tiene objeto, principios, institutos y leyes propias.

Como objeto, el Derecho Urbanístico tiene como objetivo promover el control jurídico del desarrollo urbano, es decir, de los diversos procesos de uso, ocupación, subdivisión y gestión del suelo en las ciudades. La urbanización intensiva ha sido seguramente el fenómeno socioeconómico más significativo del siglo XX, provocando cambios drásticos de todo tipo. El impacto de ese proceso en el orden jurídico no puede ser ignorado.

También los principios del Derecho Urbanístico son claros, siendo los más importantes sin duda el de la función social de la propiedad y de la ciudad, bajo el cual las demás normas e instrumentos, políticas y programas deben ser interpretados, y los conflictos resueltos. Varios otros principios importantes consagrados por el Estatuto de la Ciudad pueden ser brevemente mencionados: el del urbanismo como función pública, que no se reduce a la acción estatal; el carácter normativo de las reglas urbanísticas, que cubren no sólo la acción del poder público, sino que también actúan en el medio social y en el dominio privado; la conformidad de la propiedad urbana a las normas urbanísticas; la separación entre el derecho de construir y el derecho de propiedad, a la base de la institución del suelo creado y de la transferencia del derecho de construir. También se aplica el principio de la cohesión de las normas urbanísticas, cohesión que -como he expresado anteriormente- tiene lugar sobre la égida del principio mayor de la función social de la propiedad y de la ciudad. Otros dos importantes principios interrelacionados fueron materializados por el Estatuto de la Ciudad, a saber: el de la justa distribución de los beneficios y costos de la urbanización, por ejemplo a través de la utilización extrafiscal de la tributación, y el de la afectación de las plusvalías al costo de la urbanización, de tal forma que el poder público pueda recuperar y redireccionar a favor de la comunidad la valorización inmobiliaria que origina la inversión pública para las propiedades privadas. 
Son muchos los estatutos típicos del Derecho Urbanístico; por ejemplo, los planes (plan director, plan de acción, plan estratégi$c o$, etc.), la subdivisión del suelo urbano (loteamiento, "desmembramiento", etc.) o la zonificación, que incluye índices urbanísticos como la tasa de ocupación, el coeficiente de aprovechamiento, modelos de asentamiento, etc. Más que nunca, el Derecho Urbanístico brasileño tiene su propio conjunto de leyes propias y específicas incluyendo, más allá de las disposiciones del capítulo constitucional sobre la política urbana y del Estatuto de la Ciudad, la importante ley federal de división del suelo y otras leyes federales ambientales y relativas al patrimonio histórico-cultural, así como cientos de leyes estatales municipales.

En suma, si desde la década de 1930 la legislación urbanística estaba siendo construida para materializar el principio de la función social de la propiedad introducida por la Constitución Federal de 1934, con la aprobación del Estatuto de la Ciudad el orden jurídico-urbanístico ha sido consolidado, y necesita urgentemente ser reconocido con la debida seriedad, incluso por los temarios de las facultades de derecho.

\section{Conclusión}

La aprobación del Estatuto de la Ciudad ha consolidado el orden constitucional en cuanto al control jurídico del desarrollo urbano, con el objetivo de reorientar la acción del poder público, del mercado inmobiliario y de la sociedad de acuerdo con nuevos criterios urbanísticos, económicos, sociales y ambientales. Con todo, su efectiva materialización en las leyes -y sobre todo en las políticas públicas- depende fundamentalmente de la amplia movilización de la sociedad brasileña, dentro y fuera del ámbito estatal. El papel de los juristas en este proceso es de fundamental importancia para que sean cambiadas las bases del proceso de expoliación y de autodestrucción socioambiental que ha caracterizado el crecimiento urbano en Brasil.

\section{Referencias bibliográficas}

Alfonsin, B. de M. (1997). Direito a moradia: instrumentos e experiencias de regularizacao fundiaria nas cidades brasileiras. Rio de Janeiro: FASE/IPPUR.

(2001). "Politicas de regularizacao fundiaria: justificacao, impactos e sustentabilidade". Fernandes, E. (org.), Direito Urbanistico e Politica Urbana no Brasil. Belo Horizonte: Del Rey.

Fernandes, E. (1985). "Algumas ideias sobre a Assembleia Constituinte". Weffort, F. et al. (orgs.), Brasil: Crise e Alternativas. Belo Horizonte: Partido dos Trabalhadores/ SEGRAC.

(1992). "Juridical-institutional aspects of metropolitan administration in Brazil". Third World Planning Review, 14. (1995). Law and Urban Change in Brazil. Aldershot: Avebury. (1997). "Access to Urban Land and Housing in Brazil: Three Degrees of Illegality", Working Paper WP97EF1. Cambridge, MA.: Lincoln Institute of Land Policy.

(1998a). "Direito Urbanistico: entre a cidade 'legal' e a cidade 'ilegal'". Femandes, E. (org.), Direito Urbanistico. Belo Horizonte: Del Rey.

(1998b). "A regularizacao de

favelas: o caso de Belo Horizonte". Femandes, E. (org.), Direito Urbanistico. Belo Horizonte: Del Rey.

(1998c). "Direito e urbanizacao no Brasil". Femandes, E. (org.), Direito Urbanistico. Belo Horizonte: Del Rey. (1999a). "A regularizacao juridica das favelas no Brasil”. Saule Jr., N. (org.), Direito a Cidade. Sao Paulo: Max Limonad/Polis.

(1999b). "The Illegal City". Habitat Debate, 5, 3.

(1999c). "Redefining property rights in the age of liberalization and privatization". Land Lines, November. (org.) (2000a). Direito e

Govemanca: tendencias da gestao urbano-ambiental e a reforma do setor publico. 
Belo Horizonte: Escola de Governo da Fundacao Joao Pinheiro.

(2000b). "Law and the

production of urban illegality: urban development in Brazil". Faundez, J., M. E. Footer e J. J. Norton (eds.), Governance, Development and Globalization. London: Blackstone.

(2001a). "Land and the production of urban illegality". Land Lines, May. (2001b). "Direito Urbanistico e

Politica Urbana no Brasil". Femandes, E. (org.), Direito Urbanistico e Politica Urbana no Brasil. Belo Horizonte: Del Rey.

Fernandes, E. \& R. Rolnik (1998). "Law and Urban Change in Brazil". Illegal Cities - Law and Urban Change in Developing Countries. London: Zed Books.

Femandes, E. \& A. Varley (orgs.) (1998). Illegal Cities - Law and Urban Change in Developing Countries. London: Zed Books.
Grinberg, K. (2001). Codigo Civil e Cidadania. Rio de Janeiro: Jorge Zahar.

Maricato, E. (1996). Metropole na periferia do capitalismo: ilegalidade, desigualdade e violencia. Sao Paulo: Hucitec.

(2000). "As ideias fora do lugar e o lugar fora das ideias". Arantes, $\mathrm{O}$. et al., A cidade do pensamento unico: desmanchando concensos. Petropolis: Vozes.

Payne, G. (2001). Innovative approaches to tenure for the urban poor. London: United Kingdom Department for Intemational Development.

Rolnik, R. (1997). A Cidade e a Lei. Sao Paulo: Studio Nobel.

(org) (1999). "Regulacao urbanistica e exclusao territorial”. Polis, 32.

Saule Jr., N. (1997). Plano Diretor. Porto Alegre: Fabris.

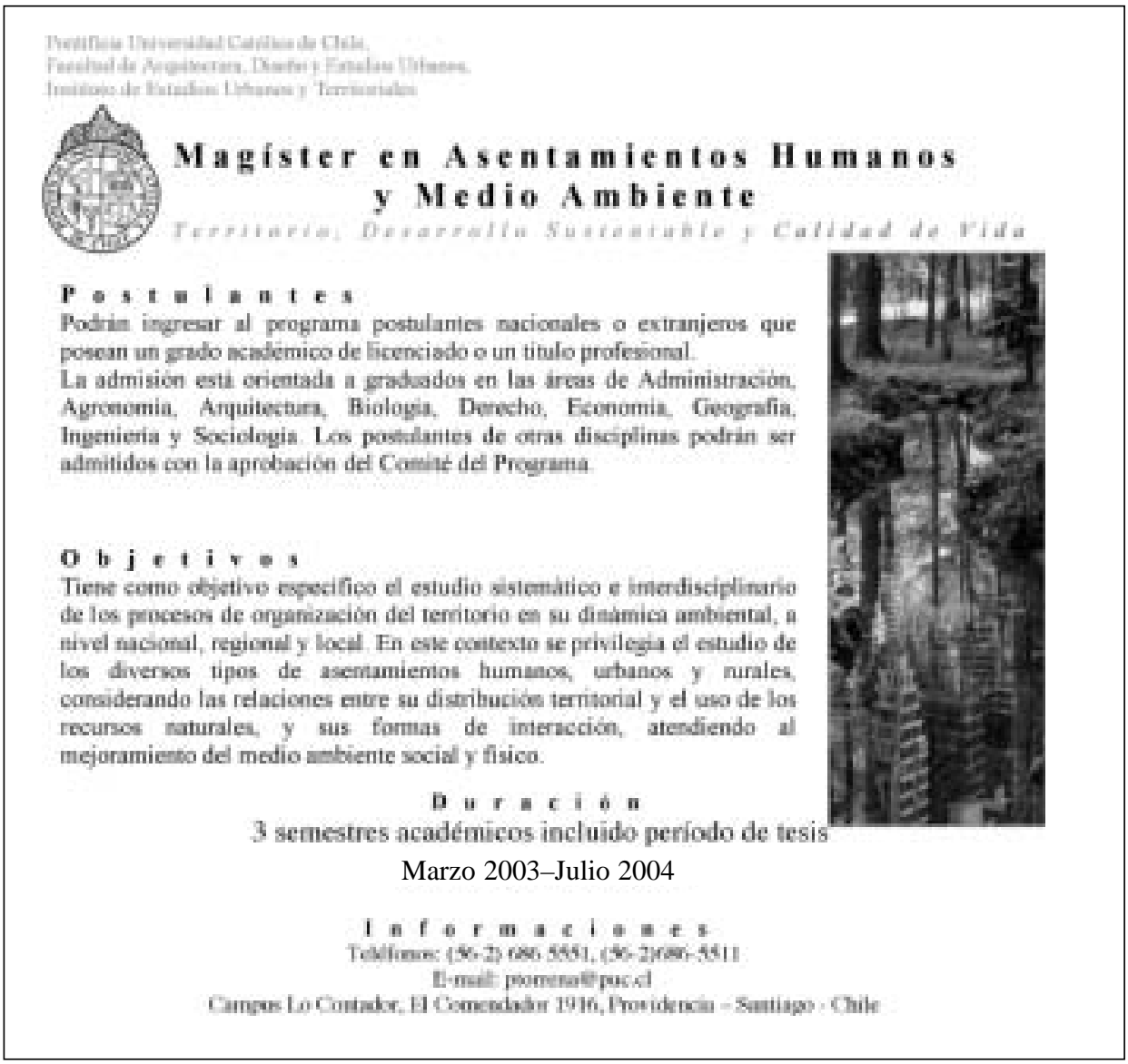

